\title{
Observational Requirements for Global-Scale Ocean Climate Analysis: Lessons from Ocean State Estimation
}

\author{
P. Heimbach ${ }^{\mathrm{a}, 1}$, G. Forget ${ }^{\mathrm{a}}$, R.M. Ponte ${ }^{\mathrm{b}}$, C. Wunsch ${ }^{\mathrm{a}}$, M. Balmaseda ${ }^{\mathrm{c}}$, \\ and (in alphabetical order): \\ T. Awaji, J. Baehr, D. Behringer, J. Carton, N. Ferry, A. Fischer, I. Fukumori, \\ B. Giese, K. Haines, E. Harrison, F. Hernandez, M. Kamachi, C. Keppenne, \\ A. Köhl, T. Lee, D. Menemenlis, P. Oke, E. Remy, M. Rienecker, \\ A. Rosati, D. Smith, K. Speer, D. Stammer, A. Weaver \\ ${ }^{\mathrm{a}} \mathrm{MIT}$, Cambridge, MA, USA \\ ${ }^{\mathrm{b}}$ AER, Lexington, MA, USA \\ ${ }^{\mathrm{c}} E C M W F$, Reading, $U K$
}

\section{Introductory comments}

Over the last decade, a number of groups have begun producing decadal-time-scale, near-global, ocean state estimates (the OceanObs'09 Community White Papers (CWP) by Lee and 26 others [2010] and Stammer and 26 others [2010] provide an overview and preliminary evaluation, respectively). Their primary purpose is the understanding of the ocean climate and its variability. Such efforts put demanding requirements on the observing system. As a bridge between the modeling and observation communities, the ocean state estimation (OCEST) groups necessarily assess the skill and deficiencies in both data sets and models. Estimation tools developed by these groups can also be used for defining observational requirements for a climate monitoring and prediction system, although

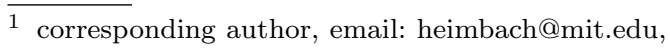
phone: +1-617-253-5259, fax: +1-617-253-4464 focus has been mainly on production of state estimates.

This white paper takes as its major premises that: (A) the climate system is truly global and must be observed globally if it is to be understood; (B) the problem of observing the ocean in its climate role involves some very long time scales; (C) all elements of the oceanic state are dynamically connected, such that measuring any specific element may contain at least some information on a much larger part of the state, and which dynamically consistent interpolators may be able to explore efficiently both forward and backward in time; (D) the ocean is a noisy fluid, full of eddies and variability across many space and time scales; a significant fraction of oceanic energy resides in fast motions (less than a month) and small space scales (less than $100 \mathrm{~km}$ ). These premises have immediate implications for observational systems design which underlie the remainder of the document.

(1) Ocean variability at any given location is a consequence of local changes, e.g., exchanges with the atmosphere, but also of internal changes originating remotely in both space and time. Many regions of the ocean are 
connected over vast distances on time scales of months to decades and beyond through a variety of dynamical processes (advection, diffusion, barotropic and baroclinic waves, airsea interactions, etc.). If one is to understand oceanic variability in any given region, one must be able to document changes that took place elsewhere, perhaps quite far in the past. Over sufficiently long time scales, no part of the ocean is disconnected from the remainder, or from the atmosphere or cryosphere at great distances. Hence, a global emphasis on observing systems becomes mandatory.

(2) The existence of long memories in the ocean (that is, long time scales of response) implies that documentation and understanding require observations on similar time scales. In practice, that means any observing system initially designed to document e.g., decadal variability, needs to ultimately be sustained indefinitely. That in turn means that a considerable expense will be incurred, and investment in understanding cost-benefit tradeoffs is worthwhile and necessary. An ongoing scientific evaluation will be required of potential new technologies, of the tradeoffs in the evolution of existing technologies, and the accommodation of new insights into the workings of the system that can have major implications for what needs to be observed and with what accuracies and precisions.

(3) Fast variability on small scales (below $\sim$ 1 month and $100 \mathrm{~km}$ ) puts a significant strain on observational systems needed for inference about ocean climate. Requirements for purposes of estimating ocean "weather" versus "climate" are not necessarily the same and decisions on future data systems must bear this in mind. For example, ocean "weather" analyses are typically concerned with coastal or regional upper ocean processes with near real-time availability of observations, whereas ocean "climate" requires longer term measurements with consistency and accuracy to discern small but large-scale variability that often span the full water column.

Drawing from the experience of OCEST groups so far, below we attempt to summarize some preliminary findings regarding present and future use of oceanic data sets. The need for quantitative assessment of future observational schemes stands out in these initial considerations. Several approaches are sketched to designing and evaluating global observing sys- tems, and that incorporate understanding of the underlying dynamics and existing knowledge. The procedures are meant to be generic, but of necessity to generate examples, assumptions have to be made about the climate fields that are of most intense interest. Thus although the temperature and salinity fields, the meridional mass and enthalpy transports are used as examples, we recognize that community conclusions about which fields are of highest priority remain to be determined. Furthermore, true experimental design involves tradeoffs between instrumental ease of use, cost, and utility. These tradeoffs can be studied using the machinery outlined here, but those specific studies are proposed for the future.

\section{Present findings}

Results from OCEST provide qualitative insight on the adequacy of present data sets regarding sampling, errors, etc. More quantitative statements must await studies such as those delineated in section 3 . The determination and attribution of regional and global sea level change provides a point in case of a stringent test of the current modeling and observational systems. The discussion in Wunsch et al. [2007] of remaining limitations, uncertainties, and required (known) error corrections may serve as an illustrative example of the various aspects that need consideration. The sea-level problem is picked up in some detail in the CWP by Nerem and 5 others [2010].

Focusing on "global" data sets, the existing system includes satellite altimetry, scatterometer wind stress, sea surface temperature, Argo profiles, surface drifters, and XBTs. Comparisons to earlier intervals, such as before Argo or satellite altimetry, show that the presentday observation system is essential and must be maintained at the very minimum.

Even with the present Argo coverage, the oceanic observing system has a number of serious shortcomings, particularly in the nearcomplete absence of deep measurements below $2000 \mathrm{~m}$ and the very poor coverage of high latitudes (including ice-covered regions). Figure 1 is a point in case of an attempt to partition regional sea-level trend into tempartureand salinity-related trends and as a function of depth. Changes are not restricted to the upper ocean, and especially in the Southern 

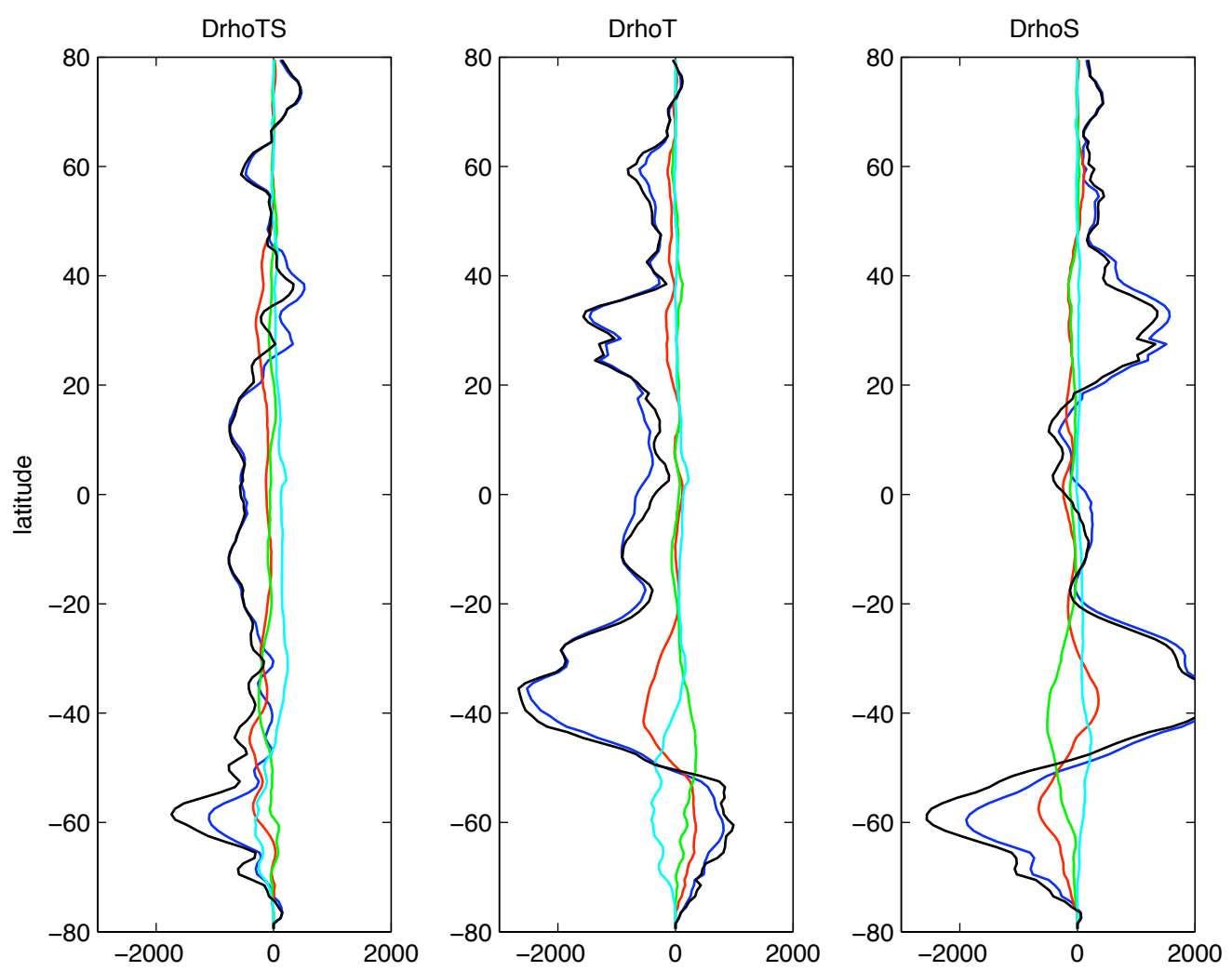

Fig. 1. Vertical integrals of zonal average combined temperature and salinity (left) and separate (middle: temperature only, right: salinity only) trends, translated into density trends (abscissa, units in $\mathrm{kg} / \mathrm{m}^{2} / \mathrm{yr}$ ) as a function of latitude (ordinate), from the updated ECCO-GODAE solution v3.73. BLACK: top-to-bottom, DARK BLUE: 0-848m, RED: 848-1975m, GREEN: 1975-2450m, CYAN: 2450-5450m. Changes are not restricted to the upper ocean, and especially in the Southern Ocean region, abyssal trends are apparent, but which are missed in estimates which rely only on current in-situ observations. In general, the deep ocean can be expected to grow in importance as the time-interval of observation is extended. Another aspect is the compensating effect of temperature and salinity. Failure to measure both may obscure inferences of trends.

Ocean, abyssal trends are apparent, but which are missed in estimates which rely only on present in-situ observations. In general, the deep ocean can be expected to grow in importance as the time-interval of observation is extended. Another aspect is the compensating effect of temperature and salinity which temperature-only observations (such as XBTs) fail to capture. The need to observe the ocean over the full water column is compelling and becomes ever more important as one looks at decadal timescales (see also the related OceanObs'09 CWP by Palmer and 21 others [2010] and Dushaw and 17 others [2010] on this issue). Possible improvements might involve extending at least some Argo oats to full-depth sampling, the addition of acoustic thermometry arrays (see Dushaw et al. [2009a] and the CWP Dushaw and 35 others [2010]), and improving bottom pressure measurements from space, which combined with sea level and with upper ocean information could help constrain the deep density eld.

Of the ancillary data sets necessary to determine the ocean climate, atmospheric forcing fluxes or state variables at the airsea interface are perhaps the most important (see the dedicated CWP by Trenberth and 7 others [2010]). The existing reanalyses (NCEP/NCAR and ECMWF/ERA-40), considered here as proxies of global surface flux observations, show major global imbalances in basic climate parameters (heat and freshwater fluxes) and these imbalances are a major obstacle to ocean state estimation for climate purposes [Wunsch et al. 2007]. Efforts by the oceanographic community to derive appropriate forcing fields (e.g.Large and Yeager [2009], Griffies and 23 others [2009a]) are very useful to enable concerted ocean modeling 
studies, but remain ad-hoc solutions. Atmospheric reanalysis projects need to address these climate-scale inconsistencies, either separately (the new ECMWF ERA-Interim and the Japanese Reanalysis (JRA-25) [Onogi and 16 others 2007] projects show promise in this respect) or through dynamically consistent coupled atmosphere/ocean/sea-ice estimation (e.g. Bengtsson and 15 others [2007]).

An equally important flux that needs to be better determined is the land freshwater input (ice melting, river runoff, ground water seepage). Very few estimates exist to date from the land hydrology community (exceptions are Fekete et al. [2002], Ngo-Duc et al. [2005a,b], although the latter NCC products do not include run-off), but their large remaining uncertainties limit their adequacy for oceanic studies. Cryospheric and gravimetric satellite missions provide one way forward (e.g., Quinn and Ponte [2008]) and need to be considered in the mix of future observational platforms. A sufficient observing system ought to provide tight enough constraints, e.g., on oceanic salt content, so as to enable independent estimation of fluxes through the surface (precipitation) and land (run-off, glacier melt). Failure to do so by any of today's (let alone past) observing or state estimation systems points to remaining serious undersampling of the ocean.

A final consideration is the consistent evaluation of uncertainties in all the data sets involved. All estimation methods rely on the provision of the errors in the data. Accuracies of present reanalysis flux products remain poorly known. Unknown biases in all data systems could particularly affect global mean quantities - recent examples for in-situ historical temperature data (mostly XBT), Argo, and altimeters are provided by Gouretski and Koltermann [2007], Willis et al. [2007], Beckley et al. [2007], Wijffels et al. [2008], and Thompson et al. [2008]. These studies show that possible biases may contaminate past data bases (in situ XBTs), recent heat content estimates (Argo), and may impact other variables in OCEST such as sea level. Particular care should therefore be given to quality control of present and past observational data sets. Any observation collected should be archived carefully with the largest information associated to the measurement procedure used. This will guarantee that the observation can be reprocessed in the future if necessary. Apart from random and systematic instrument errors, sampling errors need to be carefully considered. For climate assessment, meaningful averages need to suppress short scales (at least the Rossby radius of deformation), and high frequency noise (averaging over both barotropic and eddy time scales). The recent work of Palmer et al. [2007], Palmer and Haines [2009] has demonstrated how such noise can be removed from observations for ocean heat content calculations. Even the along-track dense sampling of altimeters leaves substantial "eddy noise" in 10-day maps of sea level variability [Ponte et al. 2007a]. Such issues are even more clear in a system like Argo [Forget and Wunsch 2007]. Density and diversity of observations need to be considered, as sampling and cross-calibration requirements are reassessed with a climate focus.

\section{Observational system design targeting climate signals}

\subsection{Overview}

A central aim of observing strategies targeting climate time scales and diagnostics (indices or metrics) is to improve understanding of the origin, propagation and growth of climate signals. Adjoint and singular vector methods are powerful practical tools to this end. They enable the detection and tracking of regions of high climate sensitivity and those that lead to optimal (defined via specified climate norms) growth of climate signals in particular.

The Lagrange multiplier or adjoint method used in state estimation provides a methodology for determining the sensitivity of various "objective" functions to perturbations in elements governing the oceanic state, including elements of the state itself (temperatures, velocities), external disturbances (meteorology), and model parameters (mixing coefficients, topography). This method has been outlined by Marotzke et al. [1999], Junge and Haine [2001], Galanti and Tziperman [2003], Köhl [2005], Bugnion et al. [2006a], Junge and Fraedrich [2007], Losch and Heimbach [2007], and others. 2

2 Note that the method assumes small perturbations around a given (nonlinear) trajectory, and may deviate from finite amplitude perturbations in the presence of strong nonlinearities, and over long time win- 

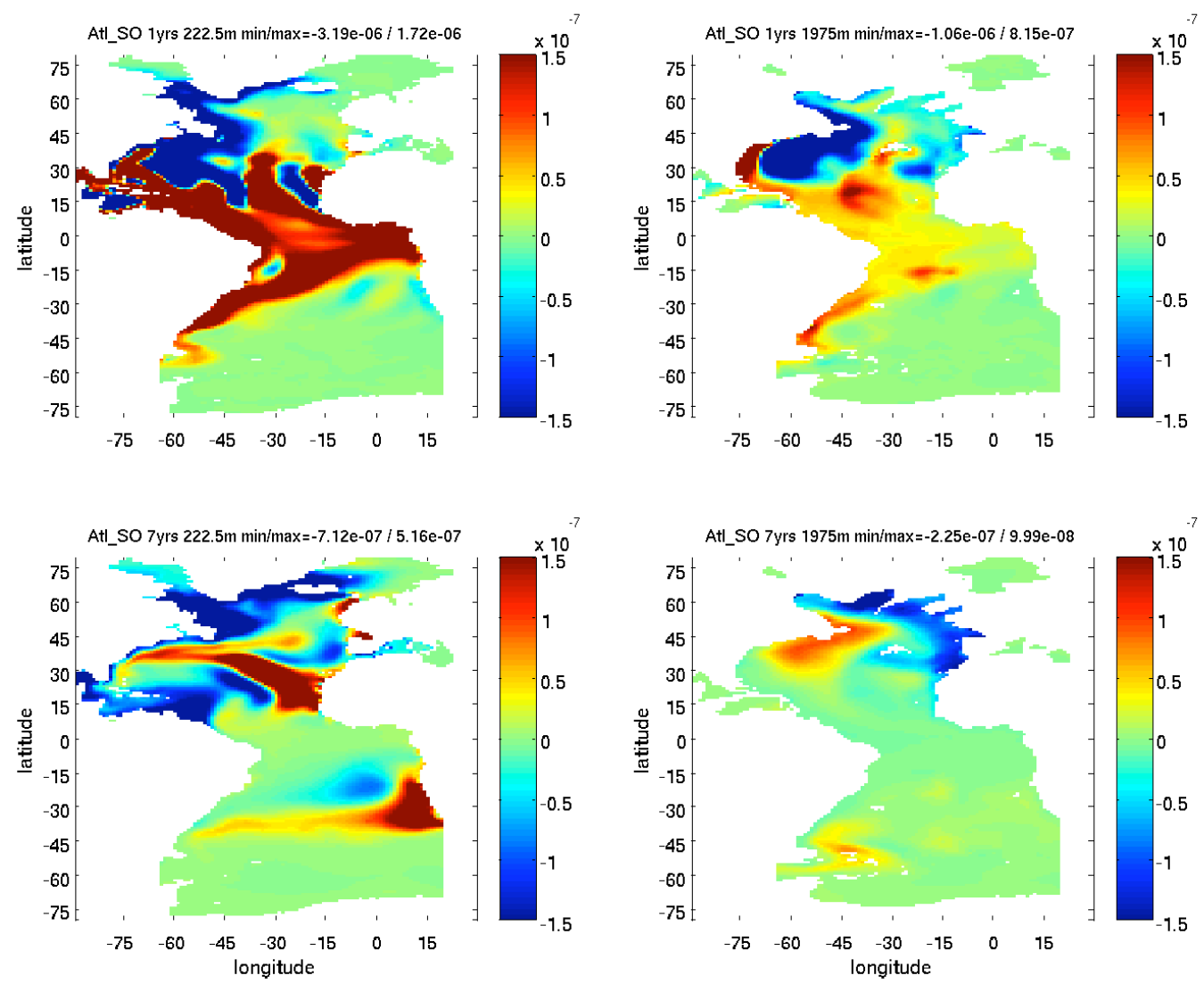

Fig. 2. Sensitivity of $J$, the meridional enthalpy transport across $25^{\circ} \mathrm{N}$, to normalized temperature perturbations 1 year (top row) and 7 years (bottom row) prior at depths 222.5 (left column) and $1975 \mathrm{~m}$ (right column).

Complementary to the calculation of adjoint sensitivities of climate diagnostics is the assessment of the adjoint in direct context of the state estimation system, i.e. where the objective function takes into account not only the climate diagnostics but also the misfit of the state estimate to the observations. The adjoint provides the information content of individual or all observations on the diagnostics of interest. The method has been developed in numerical weather prediction (NWP), mainly to assess the impact of observations on forecast skill (e.g. Langland and Baker [2004], Errico [2007], Tremolet [2008], Daescu [2008], Gelaro and Zhu [2009]), and is now being considered in the con-

dows. Still, it does provide useful sensitivities (albeit strictly those of the model or the estimation system), many aspects of which are robust features of the linearized dynamics, and which remain largely obscure in pure forward modeling studies. Assessing the usefulness of adjoint sensitivities over climate time scales and the robustness across different models remains an outstanding task. text of ocean state estimation. Also in the context of NWP [Buizza and Palmer 1995, Gelaro et al. 1998, Buizza and Montani 1999, Gelaro et al. 1999] and in the context of ENSO dynamics and prediction [Penland and Sardeshmukh 1995, Moore and Kleeman 1996, 1997a], singular vector methods have been successfully applied to derive non-normal modes which lead to optimal, transient growth of relevant norms.

For very simple systems (box models), Tziperman and Ioannou [2002] and Zanna and Tziperman [2005] have begun using singular vectors in the context of climate to study excitation mechanisms of the thermohaline circulation over decadal time scales. Very few studies exist to date which compute singular vectors for full-fledged ocean GCMs, globally, and over climate-relevant time windows. Regionally, and over short time scales, Moore et al. [2004] have established an analysis system which provides singular vectors which may be used for optimal initialisation of ensemble prediction. Fujii et al. [2008] have derived sin- 
gular vectors to infer error growth in the region of the Kuroshio meander. In an effort to close the gap toward global, climate-type studies, Zanna et al. [2010a,b] have used an idealized Atlantic GCM configuration to infer optimal perturbations of Atlantic SST anomalies, as well as Atlantic MOC variability. Of particular value is the recognition that such perturbation may not only come from surface forcing, but from internal oceanic variability. Similar studies have been performed calculating singular vectors, instead of directly from a GCM operator, via a linear inverse modeling approach [Hawkins and Sutton 2009]. Optimal patterns based on the adjoint have been computed by Sevellec et al. [2007, 2008] in the context of surface perturbations of the meridional mass and heat transport. In the context of optimal observations, Köhl and Stammer [2004] have computed approximate singular vectors to demonstrate the benefit of using such observations compared to traditional section data in twin experiments of heat transport across the Greenland-Scotland ridge.

All these studies raise serious issues with regard to error growth, required observational accuracy and coverage in the presence of nonnormal, transient amplification of small perturbations. One way to interpret the results is that regions dominating optimal initial conditions (i.e. where small initial perturbations lead to the largest amplifications) require special observational investments. In the context of predictability, the growth time scales may point to inherent limits of tracking climate signals. The role of non-normal growth in the context of climate observations and their use to understand the underlying dynamics need substantial research. One robust result, nevertheless, is the global nature of the propagation of the signals. This aspect is illustrated in more detail in the following.

\subsection{Adjoint sensitivities}

Consider any climate diagnostic or objective function, $J$, e.g., the enthalpy transport across $25^{\circ} \mathrm{N}$ in the North Atlantic. The adjoint or dual solution to the state estimate can be used to calculate the sensitivities, $\partial J / \partial X(\mathbf{r}, t)$, where $X$ is any variable of concern at location $\mathbf{r}$, at time, $t$. For purposes of this white paper we employ a modified form of the adjoint solution to the MIT-AER ECCO-GODAE state estimate (outlined by Wunsch and Heimbach [2007]). Only a sketch is given here, with a fuller account in Heimbach et al. [2011]. Thus quantitative results may differ using other models but the underlying methodology may be the same.

Some parameters $X$ are far better known than others, and although a particular sensitivity may be very great, if the parameter is not uncertain, there would be little interest in understanding how a shift would affect $J$. Thus it is useful to normalize $\delta J$ to

$$
\delta J^{\prime}=\frac{1}{d z(z)} \frac{\partial J}{\partial X(\mathbf{r}, t)} \delta X(\mathbf{r}, t),
$$

where $\delta X$ is an estimate of the uncertainty (perhaps the standard deviation), and $d z(k)$ is introduced for those variables such as ocean temperatures which are best evaluated per unit depth.

Figure 2 shows the normalized sensitivity $\delta J^{\prime}$ of the $25^{\circ} \mathrm{N}$ enthalpy transport $J$ at time $t_{f}$ to ocean temperatures at two depth levels, one and seven years prior to time $t_{f}$. Various regions of large values point to "centers of action" remote in space (away from $25^{\circ} \mathrm{N}$ ) and time which influence the $25^{\circ} \mathrm{N}$ enthalpy transport $J$ at time $t_{f}$. To the degree that one seeks to understand a fluctuation in $J$ at any given time, temperature changes at these locations at these earlier times will dominate the sensitivity relative to other regions.

As one goes further back in time, an ever larger area tends to exhibit influence. Thus Figure 3 shows the sensitivity to temperature at $2950 \mathrm{~m}$ depth 17 years back in time. To provide some context we have used the sensitivity fields to calculate transport changes for realistic perturbations (details are given in Heimbach et al., 2009): a $3 \%$ change in $J$ can be achieved from near-surface temperature perturbations in the sub-tropical North Atlantic (near the section considered at $\left.25^{\circ} \mathrm{N}\right) 1$ year back in time, but an equally large perturbation can also be achieved through perturbation at $30^{\circ} \mathrm{S}$ in the South Atlantic 1 year back in time, and larger effects are seen for perturbations in the sub-polar North Atlantic 7 years back in time. Note that apart from a few CTD sections, virtually no observations are available below $2000 \mathrm{~m}$. In particular, without observations in the deep Southern Ocean, it would be difficult to attribute a change to these areas. 


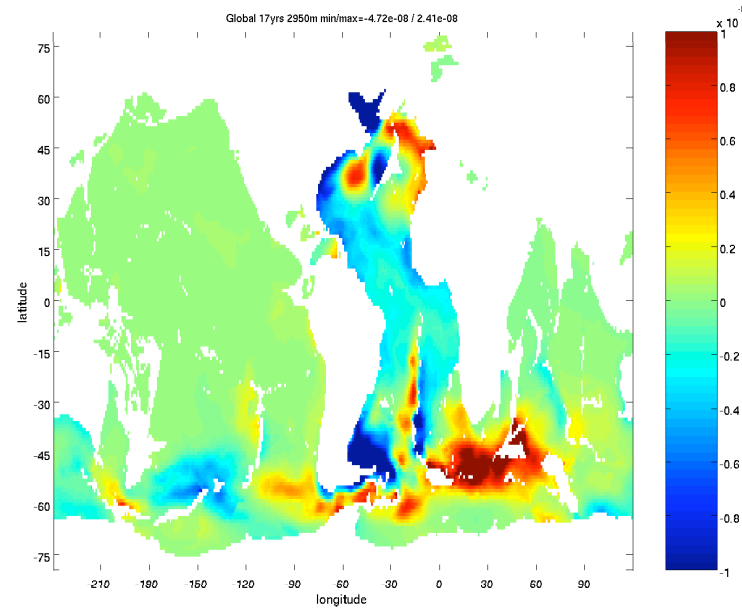

Fig. 3. Same as Figure 2 except for 17 years earlier at $2950 \mathrm{~m}$ depth.

In a first step to establish a hierarchy of influences we have also computed sensitivities to air-sea fluxes (net heat flux, freshwater flux, zonal and meridional wind stresses). As expected the strongest impact stems from the wind stress sensitivities. As an example deduced from the zonally summed sensitivities in the Atlantic, a realistic perturbation applied roughly 2 years back in time in a $5^{\circ}$ band around $45^{\circ} \mathrm{N}$, and assumed to persist over 4 days, would lead to a $5 \%$ change in $J$. The sensitivity maps indicate that larger values are possible. They also show that (normalized) heat flux sensitivities are up to an order of magnitude smaller than (normalized) wind stress sensitivities. These results, although specific to this experiment, underline that knowledge of the wind is crucial for interpreting the observed variability, and that scatterometry is expected to be a key ingredient in a climate observing system. The sensitivities move through complex pathways. Distinguishing between near-adiabatic sensitivities and those induced by heat, freshwater and mixing changes to understand water mass changes is another important goal. Design of an observational system that would hope to depict the causes and consequences of changes observed anywhere can be built upon analyses such as this one, extended to all fields which are believed to influence the ocean climate variables.

Repeating such experiments for different models, for the same and different periods, and complementing all with finite difference calculations guided by the inferred adjoint sensitivities will help to ascertain which details of the results are robust, what is the influence of the underlying model trajectory used in the linearization, and what is the time horizon over which linearization holds.

Quantitative inferences will also depend on the estimation systems used, the weights (prior uncertainties) applied, as well as the norms chosen. Research needs to address which norms are relevant, at minimum, for capturing global climate change (e.g., North Atlantic heat or mass transport, Drake Passage transport as a measure of ACC variability, North Pacific heat content, formation rates of sub-tropical mode waters or high-latitude deep waters, gobal sea level, Arctic freshwater content and sea-ice changes; a subset or all of these? serious omissions?). It will be important to identify the robustness of the results from the different estimation systems.

\section{Assessing the value of observing systems}

\subsection{Overview}

A general method for assessing the value of observing capabilities, often referred to as observing system experiments (OSE), consists in adding or withholding specific data sets in state estimates. A practical extension, often referred to as observing system simulation experiments (OSSE), which is not pursued here, consists in assessing the value of simulated data sets to guide observing system design.

A substantial body of literature has emerged that uses OSEs to assess the value of ocean observing capabilities for operational/forecasting oceanography. A review of such efforts is provided in the OceanObs'09 CWP by Lee and 9 others [2010]. For the purpose of the present white paper we focus on the climate problem which emphasizes the global nature of the circulation on time scales of years to decades and beyond.

We first summarize efforts directed at assessing the value of different components of the observing system for seasonal to inter-annual estimation and prediction. A discussion of seasonal to inter-annual estimation and prediction in the Pacific is provided in the OceanObs'09 CWP by Xue and 5 others [2010]. They highlight the role of the TAO/TRITON mooring array for monitoring, understanding and pre- 

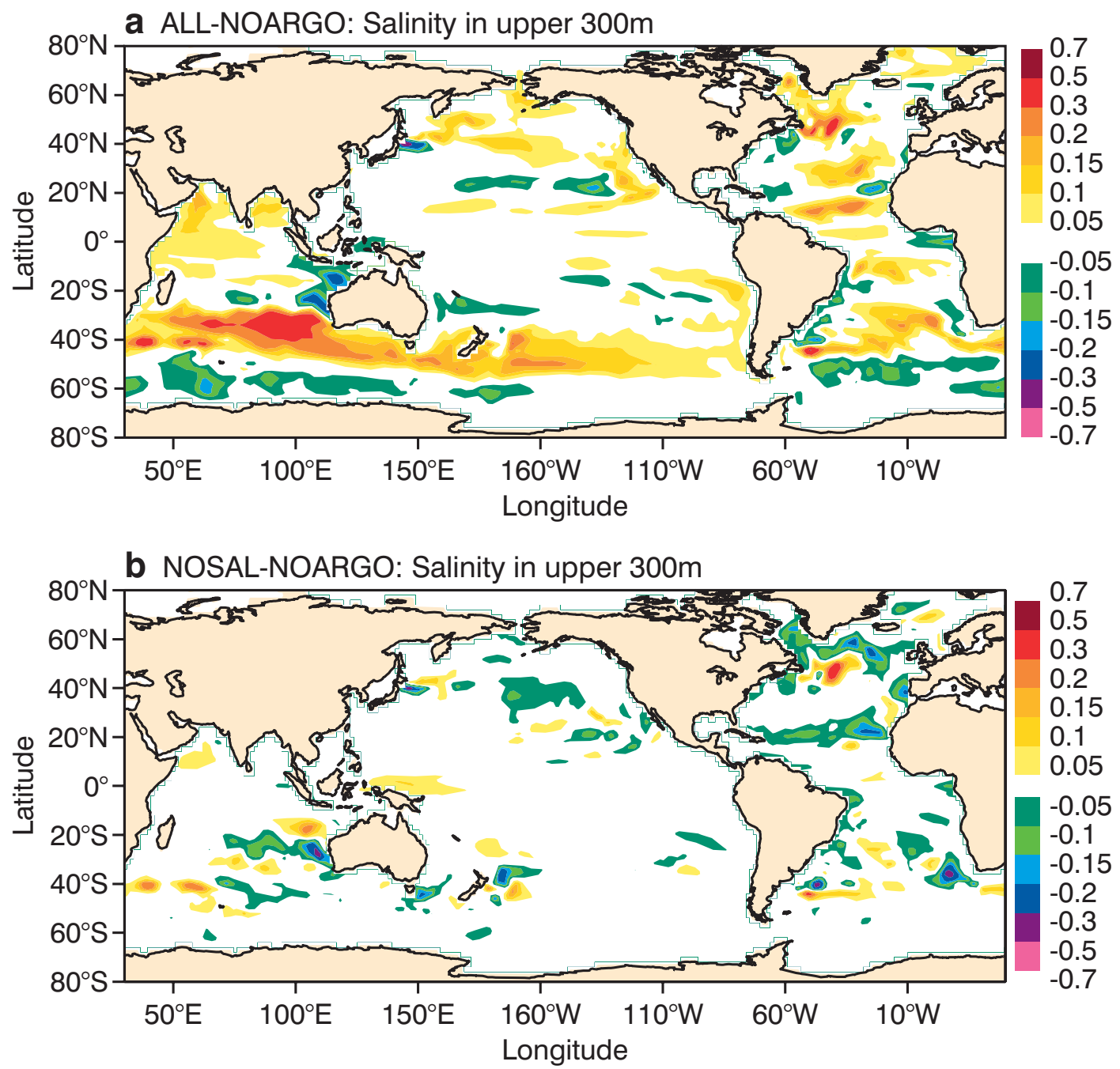

Fig. 4. Impact of Argo on the average salinity in upper 300 meters (S300). (a) Effect of Argo T and S, (b) effect of Argo T only. Units are psu.

dicting ENSO, and recommend enhancement of similar arrays in the tropical Atlantic (PIRATA) and Indian (RAMA) Ocean. On global scales Vidard et al. [2007] investigated the relative importance of the tropical in situ mooring arrays (TAO, TRITON, PIRATA), and XBTs in the analysis of the tropical oceans during the period 1993-2003. They showed a major role for the moorings (but no altimeter or Argo data were considered). Balmaseda et al. [2007] used the latest version of the ECMWF ocean data assimilation system (S3) to assess the impact on analysis of the global ocean of temperature and salinity from Argo, as well sea level from altimeter data, for the 7 year period 2001-2006.

By way of example, Figure 4 shows the impact of Argo temperature and salinity measurements on the average salinity in upper 300 me- ters (S300). Most of the changes in S300 are due directly to the use of salinity data. There are areas where the effect of T on S300 is contrary to the direct effect of using S. For instance, in the Western Pacific/Indonesian Throughflow the use of Argo temperature produces an increase of salinity, while the direct use of salinity data produces fresher water, probably associated with the barrier layer. It is likely that Argo is correcting for errors in the ocean model vertical mixing and the fresh-water flux. The information content of Argo combines well with the altimeter information in most regions. The impact of the ocean observing system on seasonal forecasts of sea surface temperature was assessed in Balmaseda and Anderson [2009]. The assimilation of ocean data improved the seasonal forecast skill in most areas, except in 
the equatorial Atlantic, where model error is a limiting factor. Smith and Haines [2009] also show the separate impacts of temperature and salinity assimilation on salinity distributions assessed from Argo, and discuss some of the mechanisms involved.

Returning to the main emphasis on process understanding on climate time scales of decadal and beyond, the value of ocean observing capabilities with respect to large scale ocean circulation diagnostics and their fluctuations on climate timescales remains largely unknown. Some preliminary analysis of OSEs for that matter can be found in Carton and Giese [2008], Stammer et al. [2007], Baehr et al. [2009], and Forget et al. [2008a,b] among others. But many outstanding questions prevail, such as the value of ocean observing systems to estimate long-term freshwater and heat transports within the global climate system.

\subsection{Adding/withholding observations}

State estimation methods can be used to evaluate the impact of different observing types and space/time distributions on climate diagnostics. As an example, we give some results described more fully by Forget et al. (2009, in preparation). Consider the restricted period between January and December 2006 (the restriction is made for computational reasons). A least-squares state estimate is made over this interval [Forget 2010] using the same methods as described in Wunsch and Heimbach [2007]. Each of the observational constraints is assigned a realistic error variance that determines its least-squares weight (the least-squares results depend upon those weights). The "baseline" state estimate $(B)$ uses only a hydrographic climatology, and the NCEP/NCAR reanalysis to constrain the MITgcm.

Then data constraints are added (individually or jointly) to the state estimate, so as to evaluate the impact of the particular data type on the previous calculation: (1) SST data in the form of the Reynolds and TMI-AMSRE monthly SST maps; (2) SSH data from the suite of altimetric satellites and a mean dynamic topography based on the recent GRACE geoid; (3) in situ temperature and salinity profiles from the Argo, XBT, TAO, and SEaOS (elephant seal) data sets. Oversimplifying some- what, one can regard the change made to any feature in a prior solution as representing an uncertainy or error reduction in that prior estimate by the presence of the new data. In a purely linear system, and with accurately chosen error variances, one can prove that new data cannot increase the uncertainty, only leave it unchanged or reduced. For present purposes, we assume that the change is representative of the error reduction.

As an example we consider the global meridional overturning circulation as a climate diagnostic (but, as noted at the end of Section 3.2 , other diagnostics may be at least as relevant in the determination of important climate observations). Figure 5 shows the differences in RMS variability of the global MOC as different data sets are added to a prior estimate. The notation is $j \mid B, a, \ldots$. where $B$ stands for the baseline data (which are always present) and $a,$. denotes any of the data sets (13 ) above; these are the prior, and $j$ is the newly introduced data type. For example, the top left panel shows the impact of adding SST, SSH and hydrography $(T S)$ data constraints jointly to the baseline estimate $(B)$. It implies that overturning uncertainties would exceed $6 \mathrm{~Sv}$ in the absence of the modern observing capabilities. While the specific value may be particular to this experiment, uncertainties of at least this magnitude are likely to prevail in 20th century state estimates, until the advent of those observing capabilities (starting to emerge in the 1980's). The other panels show the impact of individual data sets. The leading overturning constraints are from altimetry and the insitu data (mostly Argo), while SST is a weaker constraint for this quantity. As one might expect, when choosing a different "index", the relative impact of the data will likely be different, reflecting the complementarity of the various data in providing information about the climate system. For example, changes in RMS of air-sea heat fluxes are dominated by SST observations (not shown). A preliminary conclusion is that all components of the present observing system deliver important extra information, no redundancy is discernible so far, but on the contrary, serious under-sampling is more likely. 

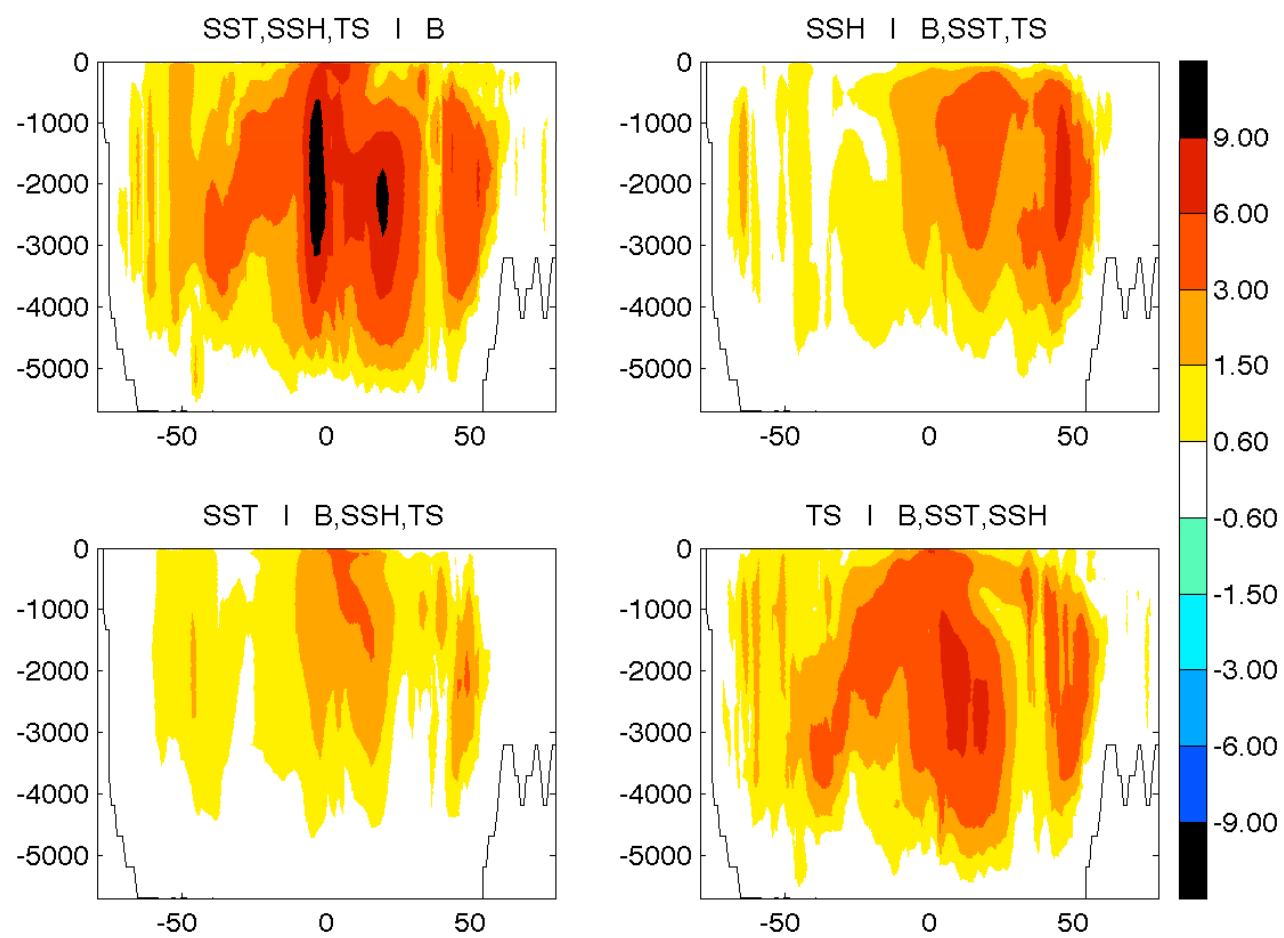

Fig. 5. Impact of modern global ocean observing capabilities on the global meridional overturning circulation. The panels show RMS variability differences between ocean state estimates, based on bi-weekly averaged fields over the year 2006. Top left: impact of jointly adding SST, SSH and in situ (TS) data to a baseline estimate consisting only of hydrographic climatology. Top right, bottom left, bottom right: impact of adding SST, SSH, and in situ (TS) data individually. Units are in Sv.

\section{Summary and outlook}

The most pressing needs for the ocean observing system, from a climate perspective (considered here are inter-annual to multidecadal time scales), include the maintenance of the current global systems (at the very minimum), the inclusion of a deep ocean component, the improvement of coverage at high latitudes, and the production of climatebalanced forcing fluxes at the air-sea and landsea boundaries. Related efforts would involve the determination of respective uncertainties and continuous evaluation of sampling requirements, upon the definition of a set of primary climate variables of interest that needs to be openly discussed in the community.

Most of the evidence today suggests that the ocean remains substantially under-sampled, thus precluding quantification of processes which contribute to observed climate variability, and hamper efforts for improved configuration of IPCC-type climate simulations. Furthermore, given the fact that virtually no continuous "deep observations" exist to date
(Argo floats are limited to $2000 \mathrm{~m}$ depth sampling an ocean of roughly $4000 \mathrm{~m}$ average depth) the issue of priority of such observations cannot be ascertained because there aren't many deep observations. Even if they were not considered a high priority today (but an unproven hypothesis) their need for deployment sooner rather than latter is mandated if one adopts the longer view. Dependent upon decisions today, climate researchers in a decade or more will, or will not, be able to begin quantifying deep oceanic changes based on adequate observations [Baker et al. 2008].

In the future a well-designed observing system should make use of the tools described in section 2 to 4, including OSE's, OSSE's, and adjoint-based systems, for which purposes better resources need to be allocated. The expectation is that these tools will enable recommendations regarding observing system trade-offs and priorities. Today's existing systems are largely proofs-of-concept of their capabilities, but need substantial investments to move beyond case-study based qualitative statements toward comprehensive quantifica- 
tion of priorities for climate observations. For example, readers will recognize that the sensitivities (in the more general sense) outlined here are dependent upon a GCM involving a number of approximations (the CWP by Griffies and 17 others [2010] summarizes some of the problems and challenges of GCM development). A legitimate question is the extent to which the inferences made would differ in a different model. A full answer requires a research effort involving the question of which model components are robust and which might in turn be sensitive to changes in e.g., resolution or parameterizations. For example, sensitivities which derive from geostrophic balance are likely to be largely model independent, whereas mixed-layer depth sensitivities could vary greatly from one model to another.

Ultimately, measures of the sensitivity of feedbacks between various processes and Earth system components will need to be considered, but this remains a long-term goal. Also largely omitted here is the discussion of the coupled climate problem, and its estimation through coupled observing system strategies. Main components are the ocean, atmosphere, and cryosphere (land and ocean), and include the global hydrologic and carbon cycle. The need for such systems is increasingly being recognized by the climate modeling community.

Acknowledgement: Supported in part by NASA, NOAA, and NSF through the National Ocean Partnership Program (NOPP), and the Estimating the Circulation and Climate of the Ocean (ECCO) project.

\section{References}

Baehr, J., Cunningham, S., Haak, H., Heimbach, P., Kanzow, T., Marotzke, J., 2009. Observed and simulated daily variability of the meridional overturning circulation at $26.5 \mathrm{n}$ in the Atlantic. Ocean Sci. 5, 575-589.

Baker, D., Schmitt, R., Wunsch, C., 2008. Endowments and new institutions for long-term observations. Oceanography 20 (4), 10-14.

Balmaseda, M. A., Anderson, D., 2009. Impact of initialization strategies and observations on seasonal forecast skill. Geophys. Res. Lett. 36, L01701. doi:10.1029/2008GL035561

Balmaseda, M. A., Anderson, D., Vidard, A., 2007. Impact of Argo on analyses of the global ocean. Geophys. Res. Lett. 34, L16605. doi:10. 1029/2007GL030452

Beckley, B. D., Lemoine, F. G., Luthcke, S. B., Ray, R. D., Zelensky, N. P., 2007. A reassessment of global and regional mean sea level trends from topex and jason-1 altimetry based on revised reference frame and orbits. Geophys. Res. Lett. 34, L14608. doi:10.1029/2007GL030002

Bengtsson, L., 15 others, 2007. The need for a dynamical climate reanalysis. Bull. Am. Met. Soc. 88(4), 495-501.

Bugnion, V., Hill, C., Stone, P., 2006a. An adjoint analysis of the meridional overturning circulation in an ocean model. J. Clim. 19(15), 3732-3750.

Buizza, R., Montani, A., 1999. Targeting observations using singular vectors. J. Atmos. Sci. 56, 2965-2985.

Buizza, R., Palmer, T., 1995. The singular-vector structure of the atmospheric global circulation. J. Atmos. Sci. 52, 1434-1456.

Carton, J., Giese, B., 2008. A reanalysis of ocean climate using simple ocean data assimilation (soda). Mon. Wea. Rev. 136 (8), 2999-3017.

Daescu, D., 2008. On the sensitivity equations of fourdimensional variational (4d-var) data assimilation. Mon. Wea. Rev. 136, 3050-3065.

Dushaw, B. D., 17 others, 2010. Progressing towards global sustained deep ocean observations. In: Hall, J., Harrison, D., Stammer, D. (Eds.), Proceedings of OceanObs'09: Sustained Ocean Observations and Information for Society. Venice, Italy, 21-25 September 2009. Vol. 2 of WPP-306. ESA Publication. doi:10.5270/0ceanObs09.cwp. 34

Dushaw, B. D., 35 others, 2010. A global ocean acoustic observing network. In: Hall, J., Harrison, D., Stammer, D. (Eds.), Proceedings of OceanObs'09: Sustained Ocean Observations and Information for Society. Venice, Italy, 21-25 September 2009. Vol. 2 of WPP-306. ESA Publication. doi:10.5270/0ceanObs09.cwp. 25

Dushaw, B. D., Worcester, P. F., Munk, W. H., Spindel, R. C., Mercer, J. A., Howe, B. M., Metzger, K., Birdsall, T. G., Andrew, R. K., Dzieciuch, M. A., Cornuelle, B. D., Menemenlis, D., 2009a. A decade of acoustic thermometry in the north pacific ocean. J. Geophys. Res. 114, C07021.

Errico, R., 2007. Interpretations of an adjoint-derived observational impact measure. Tellus 59A, 273-276.

Fekete, B., Vörösmarty, C., Grabs, W., 2002. High-resolution fields of runoff combining observed river discharge and simulated water balances. Global Biogeochem. Cycles 16 (3), 1042. doi:10.1029/1999GB001254

Forget, G., 2010. Mapping ocean observations in a dynamical framework: a $2004-2006$ atlas. J. Phys. Oceanogr. 40, 1201-1221.

Forget, G., Ferron, B., Mercier, H., 2008a. Combining argo profiles with a general circulation model in the North Atlantic. part i: estimation of hydrographic and circulation anomalies from synthetic profiles, over a year. Ocean Modelling 20 (1), 1-16. doi:10.1016/j. ocemod.2007.06.001

Forget, G., Mercier, H., Ferron, B., 2008b. Combining Argo profiles with a general circulation model in the North Atlantic. part 2: Realistic transports and improved hydrography, between spring 2002 and spring 2003. Ocean Modelling 20 (1), 17-34. doi:10.1016/j.ocemod.2007.06.002

Forget, G., Wunsch, C., 2007. Global hydrographic 
variability and the data weights in oceanic state estimates. J. Phys. Oceanogr. 37(8), 1997-2008. doi:10.1175/JP03072.1

Fujii, Y., Tsujino, H., Usui, N., Nakano, H., Kamachi, M., 2008. Application of singular vector analysis to the kuroshio large meander. J. Geophys. Res. 113, C07026.

Galanti, E., Tziperman, E., 2003. A midlatitudeENSO teleconnection mechanism via baroclinically unstable long Rossby waves. J. Phys. Oceanogr. 33, 1877-1887.

Gelaro, R., Buizza, R., Palmer, T., Klinker, E., 1998. Sensitivity analysis of forecast errors and the construction of optimal perturbations using singular vectors. J. Atmos. Sci. 55, 1012-1037.

Gelaro, R., Langland, R., Rohali, G., Rosmond, T., 1999. An assessment of the singular-vector approach to targeted observations using the fastex dataset. Q. J. R. Meteorol. Soc. 125, 3299-3327.

Gelaro, R., Zhu, Y., 2009. Examination of observation impacts derived from observing system experiments (oses) and adjoint models. Tellus 61A, 179-193.

Gouretski, V., Koltermann, K., 2007. How much is the ocean really warming? Geophys. Res. Lett. 34, L01610.

Griffies, S., 17 others, 2010. Problems and prospects in large-scale ocean circulation models. In: Hall, J., Harrison, D., Stammer, D. (Eds.), Proceedings of OceanObs'09: Sustained Ocean Observations and Information for Society. Venice, Italy, 21-25 September 2009. Vol. 2 of WPP-306. ESA Publication. doi:10.5270/0ceanObs09.cwp. 38

Griffies, S., 23 others, 2009a. Coordinated ocean-ice reference experiments (cores). Ocean Modelling 26, $1-46$.

Hawkins, E., Sutton, R., 2009. Decadal predictability of the Atlantic ocean in a coupled gcm: forecast skill and optimal perturbations using linear inverse modeling. J. Clim. 22 (14), 3960-3978. doi:10.1175/2009JCLI2720.1

Heimbach, P., Wunsch, C., Forget, G., Hill, C., Ponte, R., Utke, J., 2011. Timescales and regions of the sensitivity of atlantic meridional volume and heat transport magnitudes: Toward observing system design. Deep Sea Res. II (Special issue on the AMOC) 58, 1858-1879. doi:10.1175/2010JCLI3610.1

Junge, M., Fraedrich, K., 2007. Temperature anomalies in the northeastern north atlantic: Subpolar and subtropical precursors on multi-annual time scales. J. Clim. 20 (10), 1976-1990.

Junge, M., Haine, T., 2001. Mechanisms of North Atlantic wintertime sea surface temperature anomalies. J. Clim. 14, 4560-4572.

Köhl, A., 2005. Anomalies of meridional overturning: Mechanisms in the North Atlantic. J. Phys. Oceanogr. 35(8), 1455-1472. doi:10.1175/JP02767.1

Köhl, A., Stammer, D., 2004. Optimal observations for variational data assimilation. J. Phys. Oceanogr. 34, 529-542.

Langland, R., Baker, N., 2004. Estimation of observation impact using the nrl atmospheric variational data assimilation adjoint system. Tellus 56A, 189201.
Large, W., Yeager, S., 2009. The global climatology of an interannually varying air-sea flux data set. Climate Dyn. 33, 341-364.

Lee, T., 26 others, 2010. Ocean state estimation for climate research. In: Hall, J., Harrison, D., Stammer, D. (Eds.), Proceedings of OceanObs'09: Sustained Ocean Observations and Information for Society. Venice, Italy, 21-25 September 2009. Vol. 2 of WPP-306. ESA Publication. doi:10.5270/0ceanObs09.cwp. 55

Lee, T., 9 others, 2010. Observational requirements of godae systems. In: Hall, J., Harrison, D., Stammer, D. (Eds.), Proceedings of OceanObs'09: Sustained Ocean Observations and Information for Society. Venice, Italy, 21-25 September 2009. Vol. 2 of WPP-306. ESA Publication. doi:10.5270/0ceanObs09.cwp. 67

Losch, M., Heimbach, P., 2007. Adjoint sensitivity of an ocean general circulation model to bottom topography. J. Phys. Oceanogr. 37(2), 377-393. doi:10.1175/JP03017.1

Marotzke, J., Giering, R., Zhang, K., Stammer, D. Hill, C., Lee, T., 1999. Construction of the adjoint MIT ocean general circulation model and application to Atlantic heat transport variability. J. Geophys. Res. 104, C12, 29,529-29,547.

Moore, A., Arango, H., Di Lorenzo, E., Cornuelle, B. Miller, A., Neilson, D., 2004. A comprehensive ocean prediction and analysis system based on the tangent linear and adjoint of a regional ocean model. Ocean Modelling 7, 227-258.

Moore, A., Kleeman, R., 1996. The dynamics of error growth and predictability in a coupled model of ENSO. Q. J. R. Meteorol. Soc. 122, 1405-1446.

Moore, A., Kleeman, R., 1997a. The singular vectors of a coupled ocean-atmosphere model of ENSO. i: Thermodynamics, energetics and error growth. Q. J. R. Meteorol. Soc. 123, 953-981.

Nerem, R., 5 others, 2010. Observations of sea level change: What have we learned and what are the remaining challenges? In: Hall, J., Harrison, D., Stammer, D. (Eds.), Proceedings of OceanObs'09: Sustained Ocean Observations and Information for Society. Venice, Italy, 21-25 September 2009. Vol. 2 of WPP-306. ESA Publication. doi:10.5270/0ceanObs09.cwp. 65

Ngo-Duc, T., Laval, K., Polcher, J., Lombard, A., Cazenave, A., 2005b. Effects of land water storage on global mean sea level over the past 50 years. Geophys. Res. Lett. 32, L09704. doi:10.1029/2005GL022719

Ngo-Duc, T., Polcher, J., Laval, K., 2005a. A 53-year forcing data set for land surface models. J. Geophys. Res. 110, D06116. doi:10.1029/2004JD005434

Onogi, K., 16 others, 2007. The jra-25 reanalysis. J. Meteorol. Soc. Japan 85 (3), 369-432.

Palmer, M., 21 others, 2010. Future observations for monitoring global heat content. In: Hall, J., Harrison, D., Stammer, D. (Eds.), Proceedings of OceanObs'09: Sustained Ocean Observations and Information for Society. Venice, Italy, 21-25 September 2009. Vol. 2 of WPP-306. ESA Publication. doi:10.5270/0cean0bs09. cwp. 68

Palmer, M., Haines, K., 2009. Estimating oceanic heat 
content change using isotherms. J. Clim. in press, . Palmer, M., Haines, K., Tett, S., Ansell, T., 2007. Isolating the signal of ocean global warming. Geophys. Res. Lett. 34, L23610. doi:10.1029/2007GL031712

Penland, C., Sardeshmukh, P., 1995. The optimal growth of tropical sea surface temperature anomalies. J. Clim. 8 (8), 1999-2024.

Ponte, R., Wunsch, C., Stammer, D., 2007a. Spatial mapping of time-variable errors in jason-1 and topex/poseidon sea surface height measurements. J. Atmos. Ocean. Technol. 24 (6), 1078-1085. doi:10.1175/JTECH2029.1

Quinn, K. J., Ponte, R. M., 2008. Estimating weights for the use of time-dependent gravity recovery and climate experiment data in constraining ocean models. J. Geophys. Res. 113, C12013. doi:10.1029/2008JC004903

Sevellec, F., Huck, T., Jelloul, M., Grima, N., Viadard, J., Weaver, A., 2008. Optimal surface salinity perturbations of the meridional overturning and heat transport in a global ocean general circulation model. J. Phys. Oceanogr. 38, 2739-2754.

Sevellec, F., Jelloul, M., Huck, T., 2007. Optimal surface salinity perturbations influencing the thermohaline circulation. J. Phys. Oceanogr. 37, 27892808.

Smith, G., Haines, K., 2009. Evaluation of the $\mathrm{s}(\mathrm{t})$ assimilation method with the Argo dataset. Q. J. R. Meteorol. Soc. 135 (640), 739-756.

Stammer, D., 26 others, 2010. Ocean variability evaluated from an ensemble of ocean syntheses. In: Hall, J., Harrison, D., Stammer, D. (Eds.), Proceedings of OceanObs'09: Sustained Ocean Observations and Information for Society. Venice, Italy, 21-25 September 2009. Vol. 2 of WPP-306. ESA Publication. doi:10.5270/0ceanObs09.cwp. 85

Stammer, D., Köhl, A., Wunsch, C., 2007. Impact of the grace geoid on ocean circulation estimates. J. Atmos. Ocean. Technol. 24, 1464-1478. doi:10.1029/2007GB002923

Thompson, D., Kennedy, J., Wallace, J., Jones, P., 2008. A large discontinuity in the mid-twentieth century in observed global-mean surface temperature. Nature 453 (29), 646-649. doi:10.1038/nature06982

Tremolet, Y., 2008. Computation of observation sensitivity and observation impact in incremental variational data assimilation. Tellus 60A, 964-978.

Trenberth, K., 7 others, 2010. Atmospheric reanalyses: A major resource for ocean product development and modeling. In: Hall, J., Harrison, D., Stammer, D. (Eds.), Proceedings of OceanObs'09: Sustained Ocean Observations and Information for Society. Venice, Italy, 21-25 September 2009. Vol. 2 of WPP-306. ESA Publication. doi:10.5270/0ceanObs09. cwp. 90

Tziperman, E., Ioannou, P., 2002. Transient growth and optimal excitation of thermohaline variability. J. Phys. Oceanogr. 32, 3427-3435.

Vidard, A., Anderson, D. L. T., Balmaseda, M., 2007. Impact of ocean observation systems on ocean analysis and seasonal forecasts. Mon. Wea. Rev. 135, 409-429.

Wijffels, S., Willis, J., Domingues, C., Barker, P.,
White, N., Gronell, A., Ridgway, K., Church, J., 2008. Changing expendable bathythermograph fallrates and their impact on estimates of thermosteric sea level rise. J. Clim. 21, 5657-5672.

Willis, J. K., Lyman, J. M., Johnson, G. C., Gilson, J., 2007. Correction to recent cooling of the upper ocean. Geophys. Res. Lett. 34, L16601. doi:10.1029/2007GL030323

Wunsch, C., Heimbach, P., 2007. Practical global oceanic state estimation. Physica D 230(1-2), 197208. doi:10.1016/j.physd.2006.09.040

Wunsch, C., Ponte, R., Heimbach, P., 2007. Decadal trends in sea level patterns:1993-2004. J. Clim. 20(24), 5889-5911.

Xue, Y., 5 others, 2010. Ocean state estimation for global ocean monitoring: Enso and beyond. In: Hall, J., Harrison, D., Stammer, D. (Eds.), Proceedings of OceanObs'09: Sustained Ocean Observations and Information for Society. Venice, Italy, 21-25 September 2009. Vol. 2 of WPP-306. ESA Publication. doi:10.5270/0ceanObs09.cwp.95

Zanna, L., Heimbach, P., Moore, A., Tziperman, E. 2010a. Optimal growth of tropical Atlantic SST anomalies. J. Phys. Oceanogr. 40(5), 983-1003. doi:10.1175/2009JP04196.1

Zanna, L., Heimbach, P., Moore, A., Tziperman, E., 2010b. Optimal excitation of interannual Atlantic meridional overturning circulation variability. J. Clim. 24, 413-427. doi:10.1175/2010JCLI3610.1

Zanna, L., Tziperman, E., 2005. Non normal amplification of thermohaline circulation anomalies. J. Phys. Oceanogr. 35(9), 1593-1605. 